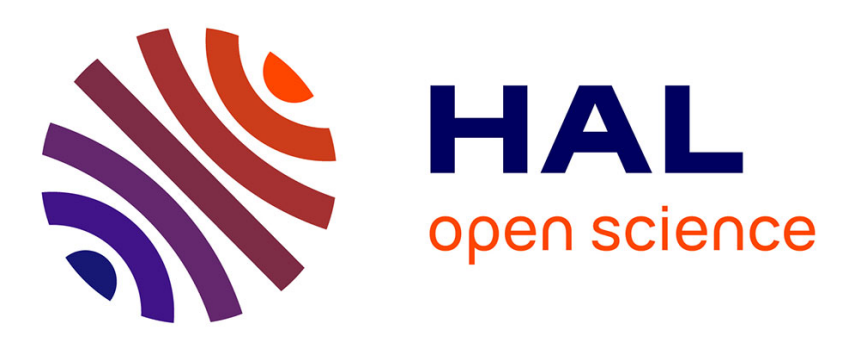

\title{
The cost of universal free access for treating HIV/AIDS in low-income countries: the case of Senegal
}

Bernard Taverne, Diop Karim, Vinard Philippe

\section{To cite this version:}

Bernard Taverne, Diop Karim, Vinard Philippe. The cost of universal free access for treating HIV/AIDS in low-income countries: the case of Senegal. Coriat, B. The Political Economy of HIV/AIDS in Developing Countries. TRIPS, Public Health Systems and Free Access, Edward Elgar, pp.273-290, 2008. ird-00403656

\section{HAL Id: ird-00403656 \\ https://hal.ird.fr/ird-00403656}

Submitted on 10 Jul 2009

HAL is a multi-disciplinary open access archive for the deposit and dissemination of scientific research documents, whether they are published or not. The documents may come from teaching and research institutions in France or abroad, or from public or private research centers.
L'archive ouverte pluridisciplinaire HAL, est destinée au dépôt et à la diffusion de documents scientifiques de niveau recherche, publiés ou non, émanant des établissements d'enseignement et de recherche français ou étrangers, des laboratoires publics ou privés. 


\title{
The cost of universal free access for treating HIVIAIDS in low-income countries: the case of Senegal
}

\author{
Taverne B. ${ }^{*}$, Diop K..**, Vinard P. ${ }^{* * *}(2008)$ \\ * UMR 145 « VIH/sida et maladies associées », IRD, <Bernard.Taverne@ird.fr> \\ ** Division de Lutte contre le Sida et les IST, Ministère de la Santé et de la Prévention, Sénégal, \\ $<$ karim_diop31@hotmail.com> \\ *** ALTER Santé Internationale, Montpellier France, <philippe.vinard@wanadoo.fr>
}

In press :

Taverne B., Diop K, Vinard P. 2008. The cost of universal free access for treating HIVIAIDS in lowincome countries: the case of Senegal. In Coriat B. (Ed.) The Political Economy of HIVIAIDS in Developing Countries. TRIPS, Public Health Systems and Free Access. London, Edward Elgar, in press.

\section{Introduction}

Since 2004, access to medical treatment for people living with HIV, including antiretroviral drugs (ARVs), has seen tremendous growth in Southern countries, through the impetus of the WHO's " 3 by 5 " programme. By the end of 2006, unanimous consensus was reached on the need to expand therapeutic treatment and prevention, using a complementary and simultaneous approach to limit the spread and impact of the HIVIAIDS epidemic in countries with limited resources (WHO, 2006).

Research completed with the first cohorts of patients treated with ARVs showed very early on that the fees for care charged to patients constituted a major obstacle to effective therapeutic treatment (Whiteside and Lee, 2005; Braitstein et al., 2006). In 2005, this observation led the WHO "to advise countries to adopt a policy of free access at the point of service delivery for an 'essential packet' of HIV care and treatment, including antiretroviral treatment" (WHO, 2005). Since 2006, the abolition of user fees at the point of service delivery for care and drugs is one of the pillars of the public health approach proposed by the WHO, within the framework of universal free access to treatment (Gilks et al., 2006).

Numerous African countries are involved in free ARV-drug distribution; very few, however, have taken the plunge in providing complete free medical treatment. Most officials who shape health policies in Africa have doubts about the feasibility of complete free access, fearing that such a decision will lead to high costs that will be impossible to bear in the short- or medium-term in relation to the country's budget.

Senegal was the first country in Africa to provide ARV drugs free of charge in 2003, as well as HIV tests, CD4 counts and treatments for several opportunistic infections. Nevertheless, by the end of 2007, treatment is still not completely free because patients must pay for their consultations, hospitalisation, biological exams and various other drugs. Current debate revolves around expanding free access to include all components of medical care.

Based on the data from several different studies in Senegal, this chapter aims to assess the economic feasibility of complete free access to treatment for HIVIAIDS in this country. This evaluation was conducted in three steps. Firstly, an estimation of patients' direct costs for treatment was calculated, using two different methods that were then compared; this estimation enabled us to calculate the additional costs that must be met by the State to implement complete free access to care for PLWHA when ARVs are already distributed free of charge in the country. Secondly, we compared the amount of additional resources needed to provide complete free access with those that were disbursed by the State for the 2002-2006 period. Finally, we projected costs for the 2007-2011 period to verify whether a policy of complete free access would be feasible based on pre-allocated funding for this period. 


\section{Background: The epidemiological situation in Senegal}

The HIVIAIDS epidemic is highly concentrated in Senegal. Prevalence is low and stable - around $1.5 \%$ among pregnant women, $0.7 \%$ in the general population, and $15 \%$ to $30 \%$ among sex workers and men who have sex with men (Meda et al., 1999; MSPM, 2006). This situation is partly attributable-with no study to prove it-to the early prevention efforts implemented on the national level, combined with a bold policy launched in 1998 to provide therapeutic treatment through antiretroviral drugs within the framework of a government programme, the Senegalese Antiretroviral Drug Access Initiative (Initiative Sénégalaise d'Accès aux médicaments Antirétroviraux ISAARV).

From the start of the programme, ARVs were subsidised to make them more readily available to people with low purchasing power. These subsidies varied between $50 \%$ and $95 \%$ of the treatment costs, and a complete subsidy was granted to those who were most destitute or those who met various social criteria (e.g. PLWHA association members). Several operational studies quickly showed the negative impact that patient drug payments had on access to care and the quality of medical follow-up (Laniece et al., 2003; Desclaux et al., 2004). The payment amounts were lowered several times until December 2003, the date when free access to ARV drugs was announced for all patients living in the country.

Initially launched in the capital, this programme was gradually expanded throughout the entire country in 2001. The decentralisation process is still under way; nevertheless, in 2007, 17 hospitals and 32 health centres provided therapeutic and social care for HIVIAIDS throughout the entire national territory. At the end of 2006, close to 5000 persons benefited from treatment including antiretroviral drugs.

Screening tests are free in all of the country's public health structures. ARVs purchased by the State are provided to patients free of charge, regardless of the therapeutic regimen (first- or second-line). CD4 counts and treatment for certain opportunistic infections (anti-tuberculosis and oral, genital and neuro-meningeal antifungal agents; Cotrimoxazole) are also provided for free. The Ministry of Health also provides various non-specified drugs (antibiotics, anti-inflammatories, iron, etc.), though sporadically, depending on the supply. However, medical treatment is not completely free since patients must pay for consultation fees, complementary exams (biological exams [other than CD4 counts] and medical imaging) hospitalisation and any drugs beyond those available (cf. above). In effect, one must pay for public health services in Senegal, regardless of the level of the health structure (health centre, regional or national hospital). Only a few diseases (tuberculosis, leprosy) and medical services (childbirth in some regions of the country) or certain social categories (persons over the age of 60) guarantee the right to partial or complete coverage for the cost of care.

\section{Methods}

The evaluation is based on the estimated direct cost of medical care for PLWHA; this estimate was calculated using two different methods. The individual costs, reported for the total number of patients requiring medical care, enabled us to estimate the difference between funding needs and the resources available to the State. A cost projection was then conducted, based on national epidemiological data used to plan for the resources needed in the coming years. The two calculation methods have been detailed below.

\section{- Calculation of individual direct costs for medical treatment}

Costs were calculated first for patients who received ARV treatment and then for patients whose immune status did not yet require ARVs.

- For patients receiving ARV treatment: the direct costs of medical care are comprised of the costs of medical treatment (antiretroviral drugs and drugs for opportunistic infections), various complementary exams necessary for diagnosis and monitoring treatment (medical imaging, biological exams [chest $X$ ray, ASAT/ALAT, blood count, glucosemia, HBV-HCB serology, tuberculin test and creatine]), hospitalisation costs and fees for consultations.

- For patients not receiving ARV treatment: the direct cost was calculated based on the protocol defined by the national recommendations, which stipulates that a medical consultation, a full blood count and a CD4 count are conducted every six months. 
- Travel costs have not been taken into account in this study, although they can clearly have a major influence on the access to care.

The direct costs of treatment were calculated using two different methods:

1) By calculating total expenses over a period of 22 months (July 2003 to April 2005) from a sample of 299 adult patients treated by triple therapy (2 NRTI $+1 \mathrm{PI}$ or NNRTI) for a median duration of 48 months (IQR [interquartile ranges]: $40-62$ ), CD4 $>200$ for $80 \%$ of patients who were from the ANRS 1290 cohort (see Box 1). This involves the calculated real costs from reimbursements for expenses covered by patients, added to expenses directly covered by the research programme

\section{The ANRS 1290 cohort}

This cohort is composed of the first 420 patients who were treated within the framework of the ISAARV programme. These people, infected by HIV-1, began their treatment between August 1998 and April 2002. They received follow-up every two months at the ISAARV programme's first four clinical sites in Dakar: the Infectious Diseases Unit and the Ambulatory Treatment Centre of Fann Teaching Hospital, and two Internal Medicine Units at Principal Hospital in Dakar. Follow-up for these patients aimed to evaluate efficacy, tolerance, adherence and the emergence of resistances to antiretroviral drugs, as well as the social impact of treatment over the long term (Etard et al., 2006). This is one of the earliest cohorts of patients treated by ARVs in Africa. Various biological and clinical exams are conducted every two months; these patients benefit from support measures for adherence that were implemented within the framework of ISAARV (association support, participation in discussion groups and social services support). All health expenses incurred by patients were reimbursed to them if they were linked to HIV infection, whether for the prescriber, the point of service delivery or the purchase of drugs, upon production of a receipt. Compensation for travelling costs was provided to people who faced transport difficulties. Precise accounting was kept on each patient's expenses.

- 2) By evaluating the theoretical costs needed to apply national treatment protocols that have been developed on the basis of the WHO guidelines (MSPM, 2005). These protocols define treatment modalities for patients (minimal frequency of medical consultations), which complementary exams to conduct and which therapeutic regimens to follow for ARV drugs and for principle opportunistic infections. The costs have been calculated based on current fees charged at the Fann Hospital (treatment reference centre), the price of ARV drugs available in Senegal (prices from the 2003 invitation to tender) and from the National Supply Pharmacy catalogue for 2005-2006 for other drugs. The amount has been estimated using an event's frequency of occurrence and the unit cost applied to this event.

The different expenditures have been divided into two categories:

- The "basic package" is made up of all services that are already provided for free by the State; these include antiretroviral drugs, CD4 counts, and some treatments for opportunistic infections (antituberculosis and oral, genital and neuro-meningeal antifungal agents; Cotrimoxazole).

- The "complementary package" includes all other medical procedures that are essential to medical treatment but which are currently paid for by patients. This packet comprises medical consultation fees, biological follow-up exams (ASAT/ALAT, blood count, glucosemia, HBV-HCB serology, tuberculin test and creatine) and medical imaging (chest X-ray), hospitalisations and drugs for opportunistic infections that are not covered by the State (for example, acyclovir for herpes virus infections, ganciclovir for CMV infections, bleomycine + vincristine for Kaposi's sarcoma, etc.).

- The feasibility of expanding universal free access was assessed using an analysis of the 2002-2006 National Strategic Plan budget, based on information provided by the Ministry of Health.

- The projection for costs for the 2007-2011 period is based on the estimated demand for treatment, calculated from information provided by the Ministry of Health (MSPM, 2006) (see Table 1), in which we have applied the unit costs defined by our study.

In 2006, it was assumed that 5000 persons were treated with ARVs. Need for ARV treatment [b] has been estimated using the standard hypothesis that $20 \%$ of seropositive persons will require ARV treatment. The growth in the number of patients who are treated [c] is based on an increase of $20 \%$ during the year 2007 , then $15 \%$ for the following years. 


\begin{tabular}{|c|c|c|c|c|c|c|c|}
\hline Year & $\begin{array}{c}\text { Total } \\
\text { PLWHA } \\
{[\mathrm{a}]}\end{array}$ & $\begin{array}{c}\text { Need for } \\
\text { ARV } \\
\text { treatment } \\
{[\mathrm{b}]}\end{array}$ & $\begin{array}{c}\text { No. of } \\
\text { persons } \\
\text { receiving } \\
\text { ARV } \\
\text { treatment } \\
{[\mathrm{c}]}\end{array}$ & $\begin{array}{c}\text { \% of } \\
\text { ARV treatment } \\
\text { coverage/need } \\
\text { [d=c/b] }\end{array}$ & $\begin{array}{c}\text { No. of } \\
\text { identified } \\
\text { PLWHA who } \\
\text { do not need } \\
\text { ARV } \\
\text { treatment [e] }\end{array}$ & $\begin{array}{c}\text { Total no. } \\
\text { of PLWHA } \\
\text { who } \\
\text { receive } \\
\text { care } \\
{[\mathrm{f}=\mathrm{c}+\mathrm{e}]}\end{array}$ & $\begin{array}{c}\text { \% of medical } \\
\text { coverage/demand } \\
\text { [g=f/a] }\end{array}$ \\
\hline 2007 & 56,310 & 11,262 & 6000 & 53 & 6000 & 12,000 & 21 \\
\hline 2008 & 58,440 & 11,688 & 6900 & 59 & 6900 & 13,800 & 24 \\
\hline 2009 & 59,810 & 11,962 & 7900 & 66 & 7900 & 15,800 & 26 \\
\hline 2010 & 61,720 & 12,344 & 10,500 & 85 & 10,500 & 21,000 & 34 \\
\hline 2011 & 63,864 & 12,773 & 11,700 & 92 & 11,700 & 23,400 & 37 \\
\hline
\end{tabular}

Table 1: Estimation of the number of seropositive persons and demand for medical treatment for the years 2007 to 2011 (National Strategic Plan, 2007-2011)

For the years 2007 to 2011, the number of persons receiving ARV treatments [c] and the number of PLWHA who have been identified but do not need ARV treatment yet [e] have been estimated based on statements provided by the Ministry of Health's Division for the Fight Against STI/HIVIAIDS in 2006. This growth is realistic when considering increased capacity due to the decentralisation process and expanded testing.

The estimated number of persons treated by ARVs for the years 2007 to 2011 may be over-estimated, since the proposed amounts would lead to a coverage rate for demand [d] close to $92 \%$. Even though it may seem excessive, this amount was used insofar as it provides a maximum estimation for potential costs.

In 2006, testing still only involved a limited number of persons and was often carried out when a clinical picture suggested HIV infection, and was therefore overdue in terms of the disease's evolution. The number of identified seropositive persons who did not yet need ARV treatment was estimated at 5000 persons in 2006 , or equal to the number of patients who were treated. For the period 2007-2011, we have estimated that the number of persons diagnosed as seropositive, but not needing treatment yet [e], will correspond to the number of patients treated by ARVs. This hypothesis will lead to increased testing, thus reaching $37 \%$ of seropositive persons in 2011 [g]; this estimate is quite realistic.

\section{Results and Findings}

First, we present the estimates for direct costs of care for PLWHA, based on the two different calculation methods described above. In addition, a distinction was made between the situations involving patients who receive ARV treatment and those involving patients who do not because their physical status does not yet require it. Since the price of ARV drugs represents a large proportion of the cost of care, and since these prices fell significantly during the period 2003-2006, we have reported relevant information concerning changes in these prices. This has been taken into consideration in calculating the overall cost of care. The second part then presents an analysis of the national budget for the fight against AIDS for the 2002-2006 period, in order to estimate the budgetary margin for manoeuvre for health authorities. Finally, in the third part, we propose a projection for expenditures that would be incurred by a decision to provide universal free access for the 2007-2011 period. 


\section{Direct Costs}

\section{- Patients treated with ARV drugs}

Table 2, below, presents estimates obtained through two calculation methods. Column A has been obtained from national recommendations for treatment and column B from real expenses incurred for patients in the ANRS 1290 cohort.

\begin{tabular}{|c|c|c|c|c|}
\hline & $\begin{array}{c}\mathrm{A} \\
\text { Estimation based on } \\
\text { national } \\
\text { recommendations [1] }\end{array}$ & & $\begin{array}{c}\text { B } \\
\text { ANRS } 1290 \\
\text { cohort survey }\end{array}$ & \\
\hline Basic package [4] & Costs: $€ /$ patient/month & $\begin{array}{c}\% \text { of } \\
\text { total } \\
\operatorname{cost}(\mathrm{A})\end{array}$ & $\begin{array}{c}\text { Costs: } \\
€ / \text { patient/month }\end{array}$ & $\begin{array}{c}\% \text { of } \\
\text { total } \\
\text { cost }(B)\end{array}$ \\
\hline ARVs [3] & $48[2]$ & $97 \%$ & 68.4 & $98 \%$ \\
\hline CD4 [3] & 1.2 & $2 \%$ & 1.7 & $2 \%$ \\
\hline Drugs [4] & 0.6 & $1 \%$ & - & $0 \%$ \\
\hline Subtotal & 49.8 & $90 \%$ & 70.1 & $89 \%$ \\
\hline \multicolumn{5}{|l|}{ Complementary Package [5] } \\
\hline Biological package [6] & 2.1 & $39 \%$ & 5.1 & $58 \%$ \\
\hline Consultations & 0.8 & $14 \%$ & 0.8 & $9 \%$ \\
\hline Hospitalisation [7] & 0.5 & $8 \%$ & 0.5 & $5 \%$ \\
\hline Other complementary exams & - & $0 \%$ & 1.2 & $14 \%$ \\
\hline Drugs for opportunistic infections & 2.1 & $39 \%$ & 1.2 & $14 \%$ \\
\hline Subtotal & 5.5 & $10 \%$ & 8.8 & $11 \%$ \\
\hline TOTAL & 55.3 & & 78.9 & \\
\hline
\end{tabular}

Table 2: Average monthly direct costs of medical care per patient.

Notes:

[1] - Therapeutic treatment guide for people living with HIV, Ministry of Health, Hygiene and Prevention, April 2005.

[2] - Weighted mean of the most frequently-used therapeutic protocols in Senegal; cost calculation based on the price list from the National Supply Pharmacy's 2003 invitation to tender.

[3] - Currently provided by the State.

[4] - Some treatments for opportunistic infections are provided free of charge by the State (e.g. treatment for tuberculosis).

[5] - The complementary package amount has been estimated using the frequency of the outbreak of an event and the unit cost involved with this event. For the ANRS cohort patients, these are costs calculated from patients' reimbursed expenses, added to expenses directly covered by the research programme (e.g. biological package).

[6] - This lump sum includes: chest X-ray, ASAT/ALAT, blood count, glucosemia, HBV-HCB serology, tuberculin test and creatine.

[7] - Hospitalisation costs have been estimated on the basis of fees charged in public structures.

The two methods used here (protocol-based vs. patient sample) converge toward comparable values for costs. The total monthly cost per patient lies between $55 €$ and $80 €$ (or $660 €$ to $960 € / y e a r$ ), using the 2003 ARV drug price list. The highest amount for patients from the ANRS cohort includes the use of some second-generation ARVs (tenofovir, lopinavir + ritonavir) that are more expensive and a more complete biological follow-up (bilirubinemia, cholesterolemia, triglyceride and prothrombin time).

The basic package that is already covered by the State (ARVs, CD4 counts and treatments for a few opportunistic infections) covers $90 \%$ of the total cost. The cost of the complementary package per patient varies between $5.5 €$ and $8.8 €$ per month (or $66 €$ to $106 € /$ year); it therefore accounts for approximately $10 \%$ of the total cost; half of these expenses are for biological exams. 


\section{- Patients who do not need ARV treatment}

The annual direct cost of medical follow-up for an HIV+ person whose clinical-immune status does not justify treatment with ARV drugs is estimated at $39 €$ (based on a medical consultation, a full blood count and a CD4 count every six months)

\section{- Evolution of ARV treatment costs}

The price of ARV drugs has undergone several reductions since the programme's inception in 1998, with the greatest decreases occurring between 2000 and 2003. Nevertheless, significant price decreases continued until 2006, allowing for a reduction of between $18 \%$ and $63 \%$ depending on the therapeutic protocol (Table 3).

\begin{tabular}{|l|c|c|c|c|c|}
\hline Therapeutic combination & $\begin{array}{c}2003 \text { prices } \\
€ / \text { month }\end{array}$ & $\begin{array}{c}2006 \text { prices } \\
€ / \text { month }\end{array}$ & $\begin{array}{c}\text { Frequency } \\
\text { of use [1] }\end{array}$ & $\begin{array}{c}2003 \text { weighted } \\
\text { mean } € / \text { month }\end{array}$ & $\begin{array}{c}2006 \text { weighted } \\
\text { mean } € / \text { month }\end{array}$ \\
\hline AZT+3TC+EFZ & 62.24 & 34.08 & $48 \%$ & 29.87 & 16.36 \\
\hline AZT+3TC+NVP & 29.49 & 18.18 & $16 \%$ & 4.72 & 2.91 \\
\hline AZT+3TC+IDV & 32.85 & 26.95 & $16 \%$ & 5.26 & 4.31 \\
\hline D4T+3TC+NVP & 21.61 & 10.24 & $8 \%$ & 1.73 & 0.82 \\
\hline D4T+3TC+EFZ & 54.36 & 26.14 & $8 \%$ & 4.35 & 2.09 \\
\hline D4T+3TC+IDV & 51.86 & 19.01 & $4 \%$ & 2.07 & 0.76 \\
\hline & & & $100 \%$ & $\mathbf{4 8 . 0 0}$ & $\mathbf{2 7 . 2 5}$ \\
\hline
\end{tabular}

Table 3: Price of the six most frequently used therapeutic combinations in Senegal, based on 2003 and 2006 supply prices and monthly weighted mean for treatment.

Note:

[1]: Frequency of use in the national programme.

The weighted mean of the six most frequently-used therapeutic protocols in the national programme is $27.25 €$ at 2006 prices. This brings the cost of the "basic package" down to $28.97 € /$ month, and the overall cost of complete care to approximately $34.30 € /$ month (412€/year) with $84 \%$ of this cost dependent on the price of ARV drugs and reagents for CD4 counts.

\section{- 2002-2006 budget for the fight against AIDS in Senegal}

To assess the feasibility of extending free access, we have compared the necessary additional resources with those that are currently mobilised.

In 2001, a strategic plan was developed to organise funding for the entire fight against HIVIAIDS (CNLS, 2001). A total amount of 92.69 Million€ $(\mathrm{M} €$ ) was projected over a five-year period. In response to the ambitious goal concerning the number of patients to be treated $(7,000$ patients in 2006), considerable budget increases were planned to purchase ARV drugs (Vinard et al., 2003). The budget allocated to ARVs should increase from 1.22M€ to 7.31M€, and the budget for reagents should double in five years to reach $69,000 €$. Budgets for opportunistic infections were estimated for an annual amount which increased from $125,000 €$ to $183,000 €$. According to these projections, the whole programme should have seen less spectacular progress, but nevertheless went from $16.7 \mathrm{M} €$ to nearly $23 \mathrm{M} €$ per year.

In the end, this programme was not fully funded; however, nearly $80.8 \mathrm{M} €$ (or over $87 \%$ ) had been promised by the State and various donors, attesting to the Senegalese programme's success. During the first three years (2002-2004), 34.56M€ - accounting for approximately half of the expenditure had been implemented. Due to a significant increase in projected expenditures for 2005 and 2006, the outstanding balance could only be relatively modest (under $4 \%$ ).

During the period 2002-2006 (see Table 4), the budget allocated to medical care for PLWHA increased from 1.98M€ to $2.36 \mathrm{M} €$; at the same time, the total health budget rose from $61.43 \mathrm{M} €$ to 116.16M€. The budget for medical care for PLWHA accounted for $3.2 \%$ of the health budget in 2002 and then stabilised at about $2 \%$ in the following years (2003 to 2006). 


\begin{tabular}{|l|c|c|c|c|c|}
\hline Millions of $€$ & $\mathbf{2 0 0 2}$ & $\mathbf{2 0 0 3}$ & $\mathbf{2 0 0 4}$ & $\mathbf{2 0 0 5}$ & $\mathbf{2 0 0 6}$ \\
\hline $\begin{array}{l}\text { Public Health Expenditure (Ministry of Health, } \\
\text { Hygiene and Prevention Budget - operations and investment) }\end{array}$ & 61.43 & 68.23 & 91.31 & 71.57 & 116.16 \\
\hline $\begin{array}{l}\text { Medical Care of PLWHA } \\
\text { (ARVs + OI + reagents) }\end{array}$ & 1.98 & 1.73 & 1.7 & 2.32 & 2.36 \\
\hline $\begin{array}{l}\text { Medical Care of PLWHA } \\
\text { /Public Health Expenditure }\end{array}$ & $3.2 \%$ & $2.5 \%$ & $1.9 \%$ & $2.1 \%$ & $2 \%$ \\
\hline
\end{tabular}

Table 4: Ministry of Health, Hygiene and Prevention budget (operations, investment) and projected budget for the purchase of ARVs, drugs for opportunistic infections and CD4 reagents over the period from 2002-2006 (source: Multisectorial Plan and Law of Finances, Senegal).

Over the period from 2002-2006, funding for drugs was primarily provided by the Senegalese State (Ministry of Health) (see Table 5), underscoring the national effort in AIDS care. International donors only intervened occasionally (2004 and 2005) in this domain; their interventions concentrated on other forms of support.

\begin{tabular}{|l|c|c|c|c|c|}
\hline Millions of $€$ & $\mathbf{2 0 0 2}$ & $\mathbf{2 0 0 3}$ & $\mathbf{2 0 0 4}$ & $\mathbf{2 0 0 5}$ & $\mathbf{2 0 0 6}$ \\
\hline Ministry of Health & 1.98 & 1.73 & 0.105 & 2.16 & 2.36 \\
\hline Global Fund & - & - & 275 & 0.15 & - \\
\hline World Bank & - & - & 776 & - & - \\
\hline Total & 1.98 & 1.73 & 1.7 & 2.32 & 2.36 \\
\hline $\begin{array}{l}\text { Amount delivered } \\
(\% \text { delivered/projected) }\end{array}$ & 0.75 & 0.95 & 1.32 & 1.57 & \multirow{2}{*}{ nda } \\
\hline
\end{tabular}

Table 5: Source of funding for ARVs, drugs for opportunistic infections and CD4 reagents, and actual amounts delivered, years 2002-2006.

The actual amounts of drugs and reagents delivered could be calculated using documentation from the National Supply Pharmacy, which handles the importation of all drugs and reagents for the national programme. During this 2002-2006 period, the amounts delivered appeared to be much lower than the funding obtained; at best, the amount delivered in 2004 corresponded to $77 \%$ of the budget obtained. This means that the State did not commit the entire available budget to purchasing ARV drugs and reagents during the period in question. One the one hand, this is due to the fact that the price of ARVs dropped significantly during this period, hence making it possible to obtain the necessary drug quantities at a low cost. On the other hand, however, it is also due to flaws in drug and reagent supply (lapses in stock management, undelivered orders) that led to brief and frequent supply breaks. Therefore, it had been possible to commit between $0.38 \mathrm{M} €$ and $1.23 \mathrm{M} €$ to supplementary expenditures, depending on the year. The budgets initially projected for patient treatment could have easily covered totally free care during the period from 2002-2006.

\section{Medium-term projection (2007-2011)}

\section{- Assessment of the cost of complete free access}

Using the estimation for demand furnished by the Ministry of Health, to which we have applied the previously calculated direct costs (basic package at $346 € / P P Y$, and complementary package at $66 € / P P Y$, total cost of $412 € / P P Y$ ), we have calculated the changes in cost for the basic package already provided by the State [a], the complementary package [b] and the cost of medical follow-up for PLWHA not needing ARV treatment [c] based on assessments of previously-charged unit costs and on the price of drugs obtained from the 2006 invitation to tender (see Table 6). 


\begin{tabular}{|c|c|c|c|c|}
\hline Year & $\begin{array}{c}\text { Cost of } \\
\text { "basic package" for } \\
\text { PLWHA on HAART } \\
\text { M€[a] }\end{array}$ & $\begin{array}{c}\text { Cost of } \\
\text { "complementary package"1 } \\
\text { of care for PLWHA on HAART } \\
\text { M€ [b] }\end{array}$ & $\begin{array}{c}\text { Cost of } \\
\text { care for PLWHA } \\
\text { not needing HAART } \\
\text { M€ [c] }\end{array}$ & $\begin{array}{c}\text { Total } \\
\text { M€ [d] }\end{array}$ \\
\hline 2007 & 2.09 & 0.39 & 0.23 & 2.70 \\
\hline 2008 & 2.40 & 0.45 & 0.27 & 3.11 \\
\hline 2009 & 2.75 & 0.51 & 0.30 & 3.56 \\
\hline 2010 & 3.65 & 0.68 & 0.41 & 4.73 \\
\hline 2011 & 4.07 & 0.75 & 0.45 & 5.27 \\
\hline
\end{tabular}

Table 6: Estimation of the cost of medical care for PLWHA, 2007-2011.

The cost of the complementary package for patients on ARVs [b] would be $0.39 \mathrm{M} €$ in 2007; in 2011, it would reach $0.75 \mathrm{M} €$; the cost of medical follow-up for PLWHA who do not need ARV treatment [c] would increase from $0.23 \mathrm{M} €$ to $0.45 \mathrm{M} €$. Therefore, complete free access would require a supplementary cost of $1.2 \mathrm{M} €$ in $2011[\mathrm{~b}+\mathrm{c}]$, this amount comprising $22 \%$ of the total amount.

\section{- Placing complete free access in the 2007-2011 budgetary estimates}

Medical and social care for PLWHA (including orphaned children and victims of AIDS) accounts for $42 \%$ of the total amount of the planned budget in the 2007-2011 National Strategic Plan.

The annual distribution of the planned budget for care relative to the total budget is illustrated in the following figure (Figure 1). It confirms that the cost of complete free access to care is fully covered by the planned budgets. The decision to expand free access to cover all care for all PLWHA would therefore not require any reallocation of the initially-estimated resources.

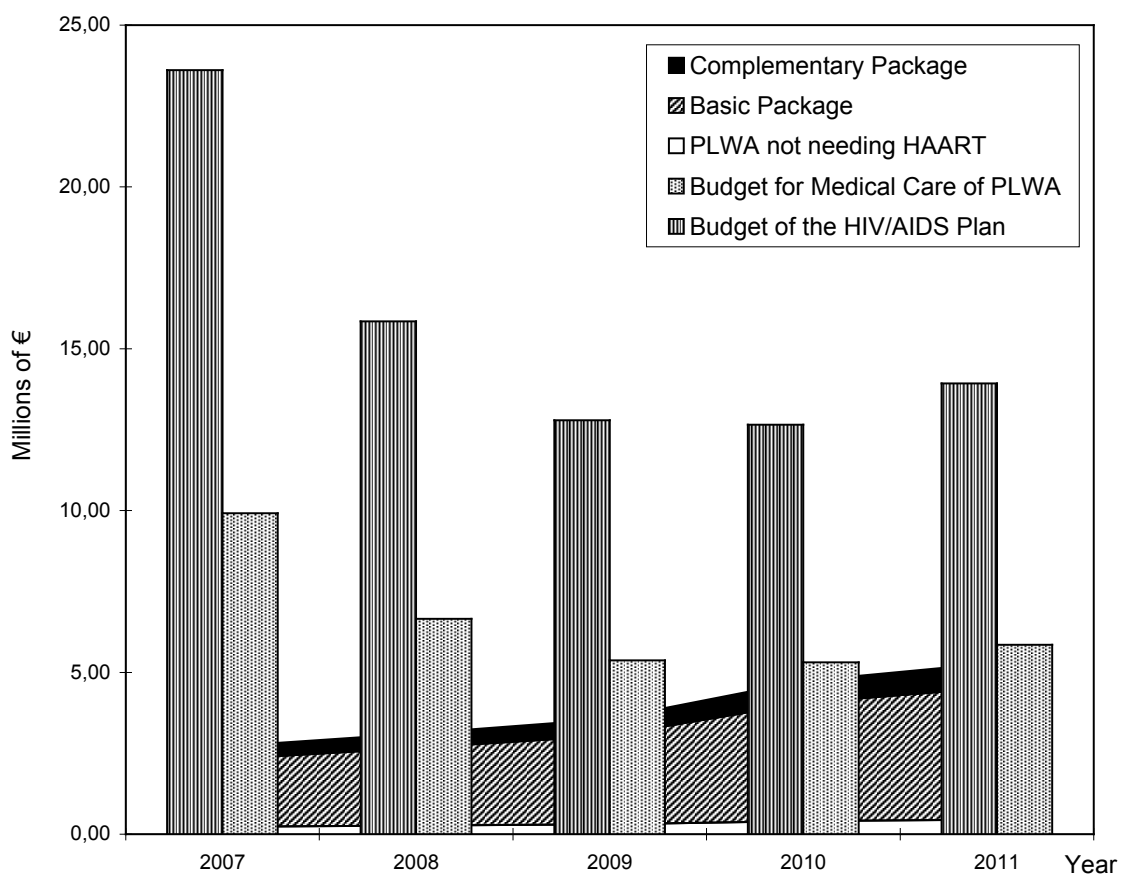

Figure 1: Total budget for the National Strategic Plan, estimated budget of the care component and cost estimations for complete care, 2007 to 2011.

\footnotetext{
1 - As defined above, namely: medical consultation fees, biological follow-up exams (ASAT/ALAT, blood count, glucosemia, HBV-HCB serology, tuberculin test and creatine) and medical imaging (chest $\mathrm{X}$-ray), hospitalisation and drugs for opportunistic infections that are not covered by the State.
} 


\section{Discussion}

This study may elicit extensive commentary because it extrapolates from an estimate of individual costs to an analysis of the national programme's overall funding and its execution. We have limited ourselves to a brief discussion of the validity of the estimations followed by an effort to place the expenses generated by complete free access in perspective relative to the programme budget and to individuals' resources. Finally, we address the issue of defining the stakes surrounding such a public health decision.

In many respects, patients in the ANRS 1290 cohort are not representative of the population of PLWHA receiving ARV treatments in Senegal. Within the framework of the research programme, they benefit from medical follow-up that is regular, standardised and much better than what is usually offered in medical consultations in the rest of the health system. No economic barrier ever arises to limit their medical consumption, since they are reimbursed for all of their health expenses. It might be assumed that this favourable context increases the demand for care and therefore leads to overestimated costs, but on the contrary, this easy access has probably allowed for earlier diagnoses for some opportunistic infections, leading to reduced treatment costs. On the other hand, it has been demonstrated that during the first 12 months of treatment, morbidity, mortality and consequently the costs of care are at their highest (Canestri et al., 2004; Etard et al., 2006). Furthermore, these patients have received medical care for a long time (median duration of ARV treatment of 48 months [IQR 40-62]); the period during which we have calculated the costs (July 2003 to April 2005) corresponds to a minimum duration of 16 months (maximum of 61 months). The clinical status for most of these patients is stabilised, which limits their health expenditures. It is expected that over the long term, costs for care will rise again with the need to move to a new - and more expensive - generation of therapeutic protocols or even due to undesirable long-term effects of ARVs. These hypotheses could not be confirmed by our study. Nevertheless, the two methods used here (based on real consumption by a sample of people and based on a protocol) furnish similar values for costs. Finally, these amounts are comparable to those calculated in other studies in Senegal (Canestri et al., 2004) and in Côte d'Ivoire (Laguide et al., 2003).

In 2006 in Senegal, the total cost of medical care for a person on ARV therapy lies around $412 €$ per year; $84 \%$ of this cost covers the price of ARVs and reagents for CD4 counts. All other necessary care components account for $16 \%$ of costs, divided between biological exams and treatment of opportunistic infections. The total annual cost of medical care for a PLWHA who does not need ARV drugs is approximately $40 €$ per year, with $90 \%$ of this amount paying for biological exams. The Senegalese State, having declared free access to ARV drugs and CD4 counts, therefore covers $84 \%$ of the costs charged to patients. This decision has had a major impact on the programme's accessibility for the entire population. Costs that currently remain under the responsibility of patients (from $67 €$ to $95 €$ per year, or less than $8 €$ per patient per month) may hardly seem high, and even negligible. However, to understand the impact that this amount could have on patients, it must be seen relative to their resources. In the region of Dakar, $60 \%$ of the population has no fixed employment or regular revenue. In $2000,60 \%$ of the people lived on less than $23 €$ per person per month to cover all of their needs (housing, clothing, food, health, education); moreover, $83 \%$ have no social protection system that allows reimbursement of health expenses (Gomes 2000). Both in their opinion and in that of the health professionals who provide their care, the costs incurred by patients constitute a major obstacle to medical follow-up for those who require ARV treatment. Since medical costs for care mainly cover ARV drugs and laboratory exams, any variation in the price of these drugs and reagents on the international market will consequently have a major effect on treatment budgets. Therefore it is essential to maintain and develop national and international initiatives to guarantee access to preferential pricing for these products in Southern countries.

Analysis of mobilisation of the 2002-2006 Strategic Plan shows that the initially-projected budget for purchasing ARVs, reagents and drugs for opportunistic infections, calculated to ensure care for 7000 patients in 2006, was fully sufficient. On the other hand, the allocations that were ultimately delivered correspond to 2002 and 2003 needs and have stagnated in 2004 and 2005, and thus become markedly lower than the programme's needs. This translated into several brief interruptions in the supply of ARV drugs and reagents in 2004, which has slowed down the number of new patients treated. These difficulties have been due to various administrative dysfunctions within the Ministry of Health (particularly concerning signing procedures for international markets). In order to treat the predicted number of patients, the actual planned budget must be mobilised, and the greatest attention should be given to logistical and organisational aspects. 
The 2007-2011 budgetary estimates signal efforts to maintain financial commitments to controlling the epidemic in the country. The experience of the 2002-2006 period shows that the major issue at the national level in terms of public health will be to promote access to care for PLWHA who require treatment with ARV drugs. Therefore the main challenge facing the State focuses less on the financial burden of extending the treatment package than it does on increasing the number of persons who are covered. This need itself depends heavily on the success of the testing policy.

\section{Conclusion}

The need for totally free medical care for PLWHA no longer needs demonstration. Funding this care allows reflection about conditions for a possible expansion in the domain of free access and contributes in a practical way to clarifying the often dogmatic debate between "payment" and "free access."

The analysis of the budgets implemented over 2002-2006 shows that while still maintaining the funding plan's initial balance, it would have been possible to free up enough supplementary funding to deal with all health expenses for PLWHA. Similarly, in terms of assessing needs for future years, it appears that the supplementary costs brought about by complete free access could be easily covered without disrupting the 2007-2011 funding plan. Hence, universal free access is budgetarily feasible. What remains to be defined is how this decision can be integrated into the current health system without creating disturbances that render it ineffective. Using the results presented in this chapter, a feasibility study was conducted to explore the various modalities that would allow for implementation of a national decision announcing complete free access to care for PLWHA. Its main results are discussed in chapter 14 of this book.

Interest in implementing complete free access can now be envisaged with respect to the expected benefits in terms of adherence and treatment quality, strengthening the health-care system and the political message linked to such a decision. Expanding free access can in effect create an opportunity to better streamline the consumption of drugs for opportunistic infections and associated treatments. In practice, this consumption, paid for by patients themselves (in public as well as private structures), rarely corresponds to optimum therapeutic protocols. Moreover, while therapeutic strategies for ARVs try to simplify protocols to reduce the number of pill intakes per day, with the aim of to improving treatment adherence, it appears that alternative or unproven treatments - which are often very expensive - are frequently prescribed. Significant savings can be obtained. It would be paradoxical to continue expending considerable effort (often with success) to reduce the constraints and costs of ARV protocols while neglecting the economic constraints associated with treatments for opportunistic infections.

Implementation of free access to care must be accompanied by the strengthening of health structures. It is obviously out of the question to ask health structures to carry this burden alone. This strengthening could take the form of budgetary support or the provision of equipment, drugs or staff to help improve the services delivered by these structures to the entire community.

From a global perspective, Senegal's experience in funding medical care for HIVIAIDS is noteworthy within the international debate about the prospects for free medical services (Nabyonga et al., 2005; McIntyre et al., 2006; Meessen et al., 2006). This debate is also a pathway to reflection on how to reestablish public funding. Once again, the fight against HIVIAIDS has played a critical role in revealing a problem that is felt within all health structures.

They authors thank the Agence Nationale de Recherche contre le Sida (ANRS) for a research grant. They also wish to thank anonymous referees of this paper for helpful comments.

\section{References}

Braitstein P, Brinkhof MWG, Dabis F et al. (2006) Mortality of HIV-1-infected patients in the first year of antiretroviral therapy: comparison between low-income and high-income countries. Lancet, $367: 817-824$. 
Canestri A, Taverne B, Thiam S, et al. (2004) Direct, Extra-ARV Medical Follow-Up Costs for Patients. In: Desclaux A, Ndoye I, Laniece I, Taverne B, (eds). The Senegalese Antiretroviral Drug Access Initiative. An Economic, Social, Behavioural and Biomedical Analysis: ANRS, UNAIDS, WHO:49-59.

CNLS (2001) Plan stratégique 2002-2006 de lutte contre le sida. République du Sénégal: Conseil National de Lutte contre le Sida.

Desclaux A, Laniece I, Ndoye I, Taverne B. (eds) (2004) The Senegalese Antiretroviral Drug Access Initiative. An Economic, Social, Behavioural and Biomedical Analysis. Paris: ANRS, UNAIDS, WHO, 230.

Etard JF, Ndiaye I, Thierry Mieg M, et al. (2006) Mortality and causes of death in adults receiving highly active antiretroviral therapy in Senegal: a 7-year cohort study. Aids; 20(8): 1181-1189.

Gilks CF, Crowley S, Ekpini R, et al. (2006) The WHO public-health approach to antiretroviral treatment against HIV in resource-limited settings. Lancet, 368:505-510.

Gomes (do E.S.) E. (2000) Étude sur l'équité dans l'accès aux soins de santé et les déterminants socio-économiques des recours aux soins dans la région de Dakar: Ministère de la Santé, FNUAP, Service de coopération et d'action culturelle.

Laguide R, Elengua N, Fassinou P, et al (2003) Direct Costs of Medical Care for HIV-Infected Children Before and During HAART in Abidjan, Côte d'Ivoire, 2000-2003. In: Moatti J-P, Coriat B, Souteyrand $\mathrm{Y}$ et al (eds). Economics of AIDS and Access to HIVIAIDS Care in Developing Countries. Issues and Challenges. Paris: ANRS: 311-327.

Laniece I, Ciss M, Desclaux A, et al. (2003) Adherence to HAART and its principal determinants in a cohort of Senegalese adults. Aids; 17 Suppl. 3:S103-S108.

Mclntyre D, Thiede M, Dahlgren G, Whitehead M. (2006) What are the economic consequences for households of illness and of paying for health care in low- and middle-income country contexts? Social Science and Medicine; 62(4): 858-865.

Meda N, Ndoye I, M'Boup S, et al. (1999) Low and stable HIV infection rates in Senegal: natural course of the epidemic or evidence for success of prevention? AIDS; 13(11): 1397-405.

Meessen B, Van Damme W, Tashobya C, Tibouti A. (2006) Poverty and user fees for public health care in low-income countries: lessons from Uganda and Cambodia. Lancet; 368: 2253-7.

MSPM (2005) Prise en charge médicale des patients vivant avec le VIH/sida au Sénégal. Dakar: Ministère de la Santé et de la Prévention Médicale, CNLS.

MSPM (2006) Données Epidémiologiques du VIH/sida au Sénégal, 2004-2005: République du Sénégal, Conseil National de Lutte Contre le Sida, Ministère de la Santé et de la Prévention Médicale, Division de Lutte Contre le Sida/IST, Laboratoire de Bactériologie et de Virologie, C.H.U. A. Le Dantec, Dakar-Sénégal, 71.

Nabyonga J, Desmet M, Karamagi H, et al (2005). Abolition of cost-sharing is pro-poor: evidence from Uganda. Health Policy and Planning; 20(2): 100-108.

Vinard P, Ciss M, Taverne B, Ly A, Ndoye I. (2003) Analysis of HIVIAIDS Expenditures in Senegal: from Pilot Project to National Program. In: Moatti $\mathrm{J}$ et al (eds). Economics of AIDS and Access to HIVIAIDS Care in Developping Countries. Issues and Challenges. Paris: ANRS: 459-482.

Whiteside A, Lee S. (2005) The "Free by 5" Campaign for Universal, Free Antiretroviral Therapy. PLoS Med, 2(8): e227.

WHO (2005) The practice of charging user fees at the point of service delivery for HIVIAIDS treatment and care. WHO Discussion Paper, WHO/HIV/2005.11.4.

WHO (2006) Progress on global access to HIV antiretroviral therapy on "3 by 5 " and beyond: WHO, 2006. 